www.jmscr.igmpublication.org

Impact Factor 5.84

Index Copernicus Value: 83.27

ISSN (e)-2347-176x ISSN (p) 2455-0450

crossref DOI: _https://dx.doi.org/10.18535/jmscr/v5i3.210

Journal Of Medical Science And Clinical Research

\title{
Maternal and Neonatal Determinants of Neonatal Jaundice - A Case Control Study
}

\author{
Authors \\ Sudha Menon ${ }^{1}$, Nadia Amanullah ${ }^{2}$ \\ ${ }^{1}$ Additional Professor, Department of Obstetrics and Gynecology, Government Medical College \\ Trivandrum, Kerala, South India \\ ${ }^{2}$ Msc Nursing Student, Government Nursing College, Trivandrum \\ Corresponding Author \\ Dr Sudha Menon \\ Email: smprasadam@gmail.com
}

\begin{abstract}
Neonatal jaundice a common condition which affects about 60-80\% of newborn and if severe can lead serious neurological sequelae. Determinants include neonatal and maternal factors. A prospective case control descriptive study in a tertiary care centre was done in 62 consecutive cases with neonatal jaundice and 124 consecutive newborns without jaundice served as controls. The major determinants for neonatal jaundice were low birth weight $<2.5 \mathrm{~kg}$ (OR $24.5495 \%$ CI $10.98-54.84$ : P<0.0001), birth asphyxia (OR 16.5; 95\% CI 4.63- 58.76, P<0.0001), Low APGAR score <7( OR 26.1; 95\% CI 3.28-207.47, P=0.0002), prematurity <37weeks ( OR $28.9295 \%$ CI 12.15-68.82 P=0.0001) Preterm premature rupture of membranes (OR $58.5795 \%$ CI 7.67 -449.87 P<0.0001) and malpresentation (OR $14.6495 \%$ CI 3.16 67.792 tailed $p=0.00004)$. The factors which evolved significant on logistic regression were Preterm premature rupture of membranes, gestational age <37 weeks, APGAR score below 7, Birth weight below 2500 grams, Birth asphyxia and multiple pregnancy. The association was less strong for $A B O$ incompatibility, antepartum hemorrhage and intrauterine growth retardation (IUGR). Meticulous antenatal care of these high risk pregnancies and intrapartum and post partum care will help in reducing the occurrence of neonatal jaundice.

Keywords: Neonatal jaundice, Determinants, Preterm Premature Rrupture of Membranes, APGAR.
\end{abstract}

\section{INTRODUCTION}

Neonatal jaundice is a very common condition affecting nearly $60-80 \%$ of the new born to a variable degree world over ${ }^{1}$. If severe jaundice develops it can lead acute bilirubin encephalopathy $(\mathrm{ABE})$ or kernicterus with a significant risk of neonatal mortality and the long-term neurodevelopmental sequelae such as cerebral palsy, sensorineural hearing loss, intellectual difficulties or gross developmental delays $2,3,4$. Hence early detection of infants at risk of severe hyperbilirubinemia is necessary to facilitate timely and effective prevention of the associated burden and is essential ${ }^{5}$. In a recent review, sub-Saharan Africa and South Asia were reported as the leading contributors to an estimated 1.1million babies who would develop severe hyperbilirubinemia worldwide every year ${ }^{6}$. Early identification of 
infants at risk of severe hyperbilirubinemia is therefore, even more crucial for this potentially devastating condition.

Based on many studies, several maternal and neonatal risk factors have been idenfitifed as risk factors for neonatal jaundice. Maternal determinants include pregnancy induced hypertension, gestational hypertension preeclampsia eclampsia, gestational diabetes mellitus, parity, gestational age, multiple pregnancy, premature rupture of membranes, anemia, antepartum hemorrhage, urinary tract infections, $\mathrm{ABO}$ incompatibility. Neonatal determinants of neonatal jaundice include prematurity, birth weight, IUGR (intrauterine growth retardation), cephal hematoma and metabolic abnormalities, neonate's gender, birth weight, frequency of nutrition and defecation, birth trauma, and history of jaundice among siblings as well as mode of delivery ${ }^{7,8}$. Excessive use of oxytocin and caesarian section have also been considered as risk factors. ${ }^{7}$

This study aims at identifying the maternal and neonatal factors which increase the risk of neonatal jaundice which help in evolving strategies to reduce the occurrence. Moreover this data can be used to evolve strategies to train health workers at community level to identify high risk mothers and high risk neonates after discharge from the hospital for early referral for prompt treatment.

\section{MATERIAL AND METHODS}

This was a prospective case control descriptive study done at a tertiary care referral centre in Trivandrum Kerala. Neonates with jaundice as assessed by Krammer Index who required treatment phototherapy or exchange transfer during first 3 days of life formed cases. Neonates without clinical evidence of jaundice within first three days of life were controls. Consecutive sampling technique was used.

Inclusion Criteria: Neonates with jaundice within first 3 days of life who required phototherapy or exchange transfusion, with mothers willing to participate in the study.
Exclusion Criteria: 1) suspected other cause of jaundice; 2) parents' unwillingness to cooperate with the study; 3) inadequate information about pregnancy or delivery 4) other neonatal symptoms such as congenital abnormalities

Data collected by interview with the mothers and review of case records of the hospital. A checklist consisting of demographic, neonatal, and maternal information was used for data collection. The neonatal information included hospitalization, method of feeding, blood group, laboratory test results, and therapeutic interventions. Moreover, maternal information including pregnancy and delivery problems, mode of delivery, and anesthesia was collected. Informed consent was taken from the mother after explaining the purpose of the study.

\section{STATISTICAL ANALYSIS}

Quantitative data were presented as a mean and standard deviation (SD), and compared by oneway Analysis of variance or, if normality or homoscedasticity assumptions, were violated Mann-Whitney $U$-test. Data analysis was done using SPSS software version19. Calculation of descriptive statistics (mean and standard deviation) and frequency tables were used. Odds ratios (ORs) and $95 \%$ confidence intervals (CIs) were estimated for severe hyperbilirubinemia of various risk factors by using univariate and multivariate logistic regression models. $P \leq 0.05$ or a $95 \%$ CI for OR_1.0 was defined as statistically significant. Analysis of variance was used to examine the association of the maternal and neonatal factors were analyzed by chi square method and Fisher's exact test. Logistic regression analysis was used to identify significant associations. P-values less than 0.05 were considered statistically significant.

\section{RESULTS}

The 62 consecutive neonates admitted with jaundice were included as cases and 124 consecutive new borns without jaundice formed the controls. Mean age of the mother in the case 
group was $25.97 \pm 4.54$ years and control group was $24.83 \pm 3.68$ years $(\mathrm{P}=0.09)$. Maternal education status and number of ante natal visits were comparable in the two groups. Among the neonates, 33(53.2\%) of 62 with jaundice and 64 $(51.6 \%)$ of 124 without Neo natal jaundice were males $\left(x^{2}=0.043 ; P=0.84\right)$. The association of various Neonatal determinants with neonatal jaundice is given in table 1 and maternal determinants is given in figure 2 .

Fetal determinants of neonatal jaundice are given in Table 2. Low birth weight was seen more commonly [50(80.6\%) vs. $18(14.5 \%) p=0.0001]$ in neonates with jaundice than those without. Birth asphyxia was seen more commonly in neonates who developed jaundice [18(29\%) vs $3(2.4 \%) p=0.0001]$. Cephal hematoma and neonatal sepsis occurred in 1 patent each in the group with jaundice. Low APGAR score $(<7)$ was also associated with neonatal jaundice $(11(17.74 \%) \quad$ vs. $1 \quad(0.81 \%) \quad \mathrm{p}=0.00003$. Intrauterine growth retardation was more frequent in neonates with jaundice than those without it [13(20.96\%) vs. 5(4.0\%) $\mathrm{P}=0.0002$ ) (figure 1).
Analysis of maternal determinants showed, that neonatal jaundice was more strongly associated with prematurity (gestational age <37 weeks: 43(69.4\%) vs.9(7.26) $\mathrm{p}=0.0001$; Phi +0.65$)$ and premature preterm rupture of membranes ( $20(32.3 \%)$ vs. $1(0.81 \%) \mathrm{p}=<0.0001$,Phi +0.47$)$. )]. Malpresentation and $\mathrm{ABO}$ incompatibility were also had association with development of neonatal jaundice but the association was less strong (Phi +0.32 and +0.31) (table2). Maternal anemia, antepartum hemorrhage and multiple pregnancies also were associated with neonatal jaundice.

Multivariate Logistic regression analysis of the neonatal jaundice showed significant association NNJ with the various factors analyzed in this study. Significant associations were noted between preterm premature rupture of membranes (PPROM), gestational age <37 weeks, APGAR $<7$, birth weight <2500grams, Birth Asphyxia, multiple pregnancy, ABO incompatibility. Less stronger associations were noted with antepartum hemorrhage and Intra uterine growth retardation (IUGR)(table 3).

Table 1 : Neonatal determinants of neonatal jaundice

$\begin{array}{lcc}\text { Item } & \begin{array}{c}\text { Cases } \mathbf{n}(\%) \\ \text { Low Birth weight }\end{array} & \begin{array}{c}\text { Controls n(\%) } \\ 18(14.51)\end{array} \\ (<2.5 \mathrm{~kg}) & & \\ \text { Birth Asphyxia } & 18(29.03) & 3(2.42) \\ \text { Apgar }<7 & 11(17.74) & 1(0.81) \\ \text { IUGR } & 13(20.96) & 5(4.03) \\ \text { *Chi- square with Yates correction applied in relevant cases } \\ \text { ** Fisher's Exact test of probability }\end{array}$

$\begin{array}{ccc}\mathrm{X}^{2} & \text { P value } & \text { Phi } \\ 77.93 & \mathrm{P}<0.0001 & +0.65 \\ & & \\ 26.63 & \mathrm{P}<0.0001 & +0.4 \\ & \mathrm{p}=0.00003^{\#} & +0.32 \\ 13.56 & \mathrm{P}=0.0002^{* *} & +0.27\end{array}$

Table 2: Maternal determinants of neonatal jaundice

\begin{tabular}{|c|c|c|c|}
\hline Item & & $\begin{array}{l}\text { Cases } \\
\text { n( \%) }\end{array}$ & $\begin{array}{c}\text { Controls } \\
\mathbf{n}(\%)\end{array}$ \\
\hline Primipara & & $42(67.8)$ & $61(49.2)$ \\
\hline $\begin{array}{l}\text { Gestational age } \\
\text { weeks }\end{array}$ & $<37$ & $43(69.4)$ & $9(7.26)$ \\
\hline Gestational HTN & & $13(21)$ & $11(8.9)$ \\
\hline APH & & $12(19.35)$ & $5(4.03)$ \\
\hline Malpresentation & & $12(19.35)$ & $2(1.61)$ \\
\hline Multiple pregnancy & & $8(12.91)$ & $2(1.61)$ \\
\hline Maternal anemia & & $9(14.52)$ & $2(1.61)$ \\
\hline $\mathrm{ABO}$ incompatability & & $22(35.48)$ & 12(9.68) \\
\hline PPROM & & $20(32.26)$ & $1(0.81)$ \\
\hline
\end{tabular}

$\begin{array}{ccc}\mathrm{X}^{2} & \text { P value } & \text { Phi } \\ 5.75 & 0.019 & +0.18 \\ 79.13 & <.0001 & +0.65 \\ & & \\ 5.38 & 0.034^{* *} & +0.17 \\ 11.69 & 0.001^{* *} & +0.25 \\ & 0.00004^{* *} & +0.32 \\ & 0.002^{* *} & +0.24 \\ & 0.001^{* *} & +0.26 \\ 18.43 & <.0001 & +0.31 \\ & <.0001^{* *} & +0.47\end{array}$


Table 3: Logistic regression analysis of the risk factors for neonatal jaundice

\begin{tabular}{|l|c|c|c|c|c|c|}
\hline Significant Risk factors & B & SE & Wald & DF & Significance & Exp(B) \\
\hline PPROM $^{\#}$ & 4.07 & 1.54 & 8.53 & 1 & 0.003 & 72.4 \\
\hline $\begin{array}{l}\text { Gestational Age } \\
\text { weeks }\end{array}$ & 3.36 & 1.36 & 7.54 & 1 & 0.006 & 63.2 \\
\hline APGAR <7 & 3.26 & 1.33 & 7.28 & 1 & 0.002 & 13.28 \\
\hline Birth weight <2.5 kg & 3.20 & 1.27 & 5.06 & 1 & 0.009 & 9.51 \\
\hline Birth Asphyxia & 2.80 & 1.26 & 4.71 & 1 & 0.003 & 15.4 \\
\hline Multiple pregnancy & 2.20 & 1.09 & 4.21 & 1 & 0.020 & 11.2 \\
\hline ABO incompatability & 1.64 & 1.18 & 4.39 & 1 & 0.036 & 5.34 \\
\hline Antepartum hemorrhage & 1.74 & 1.20 & 3.28 & 1 & 0.04 & 11.6 \\
\hline IUGR $^{*}$ & 1.84 & 0.8 & 4.39 & 1 & 0.049 & 5.34 \\
\hline
\end{tabular}

\# PPROM preterm premature rupture of membranes* IUGR Intrauterine growth retardation

Table 4 : The Odds ratio of the various determinants of neonatal jaundice

$\begin{array}{lcccccc}\text { Item } & \text { Cases n( \%) } & \begin{array}{c}\text { Controls } \\ \mathbf{n}(\mathbf{\%})\end{array} & \text { OR } & \mathbf{9 5 \%} \mathbf{C I} & \text { Phi } & \text { P } \\ \text { Prematurity } & & & & & \\ \text { (<37weeks) } & 43(69.4) & 9(7.26) & 28.92 & 12.15-68.15 & \mathbf{+ 0 . 6 5} & <0.0001 \\ \text { LBW }(<2.5 \mathrm{~kg}) & 50(80.65) & 18(14.51) & 24.54 & 10.98-54.83 & \mathbf{+ 0 . 6 5} & <0.0001 \\ \text { PPROM } & 20(32.26) & 1(0.81) & 58.57 & 7.63-449.87 & \mathbf{+ 0 . 4 7} & <0.0001^{*} \\ \text { Birth asphyxia } & 18(29.03) & 3(2.42) & 16.5 & 4.63-58.76 & \mathbf{+ 0 . 4} & <0.0001^{*} \\ \text { Malpresentation } & 12(19.35) & 2(1.61) & 14.64 & 3.16-67.79 & \mathbf{+ 0 . 3 2} & 0.00004^{*} \\ \text { APGAR < } & 11(17.74) & 1(0.81) & 26.53 & 3.34-210.88 & \mathbf{+ 0 . 3 2} & 0.00002^{*} \\ \text { ABO incompatability } & 22(35.48) & 12(9.68) & 33.55 & 7.55-149.01 & \mathbf{+ 0 . 3 1} & <0.0001^{\#} \\ \text { IUGR } & 13(20.96) & 5(4.03) & 6.31 & 2.14-18.66 & \mathbf{+ 0 . 2 7} & 0.0004^{\#} \\ \text { Maternal anemia } & 9(14.52) & 2(1.61) & 10.34 & 2.16-49.58 & \mathbf{+ 0 . 2 6} & 0.0004^{*} \\ \text { APH } & 12(19.35) & 5(4.03) & 6.62 & 1.88-16.78 & \mathbf{+ 0 . 2 5} & 0.007^{\#} \\ \text { Multiple pregnancy } & 8(12.91) & 2(1.61) & 9.04 & 1.86-43.97 & \mathbf{+ 0 . 2 4} & 0.003^{*} \\ \text { Primipara } & 42(67.8) & 61(49.2) & 2.17 & 1.15-4.11 & +0.18 & 0.02 \\ \text { Gestational HTN } & 13(21) & 11(8.9) & 2.68 & 1.12-6.39 & +0.17 & 0.04\end{array}$

*Fisher' exact test \# Chi square test with Yates correction

LBW - low birth weight, PPROM - preterm premature rupture of membranes,IUGR- intrauterine growth retardation,APH antepartum hemorrhage , HTN - hypertension

Figure 1 : Foetal determinants of neonatal jaundice

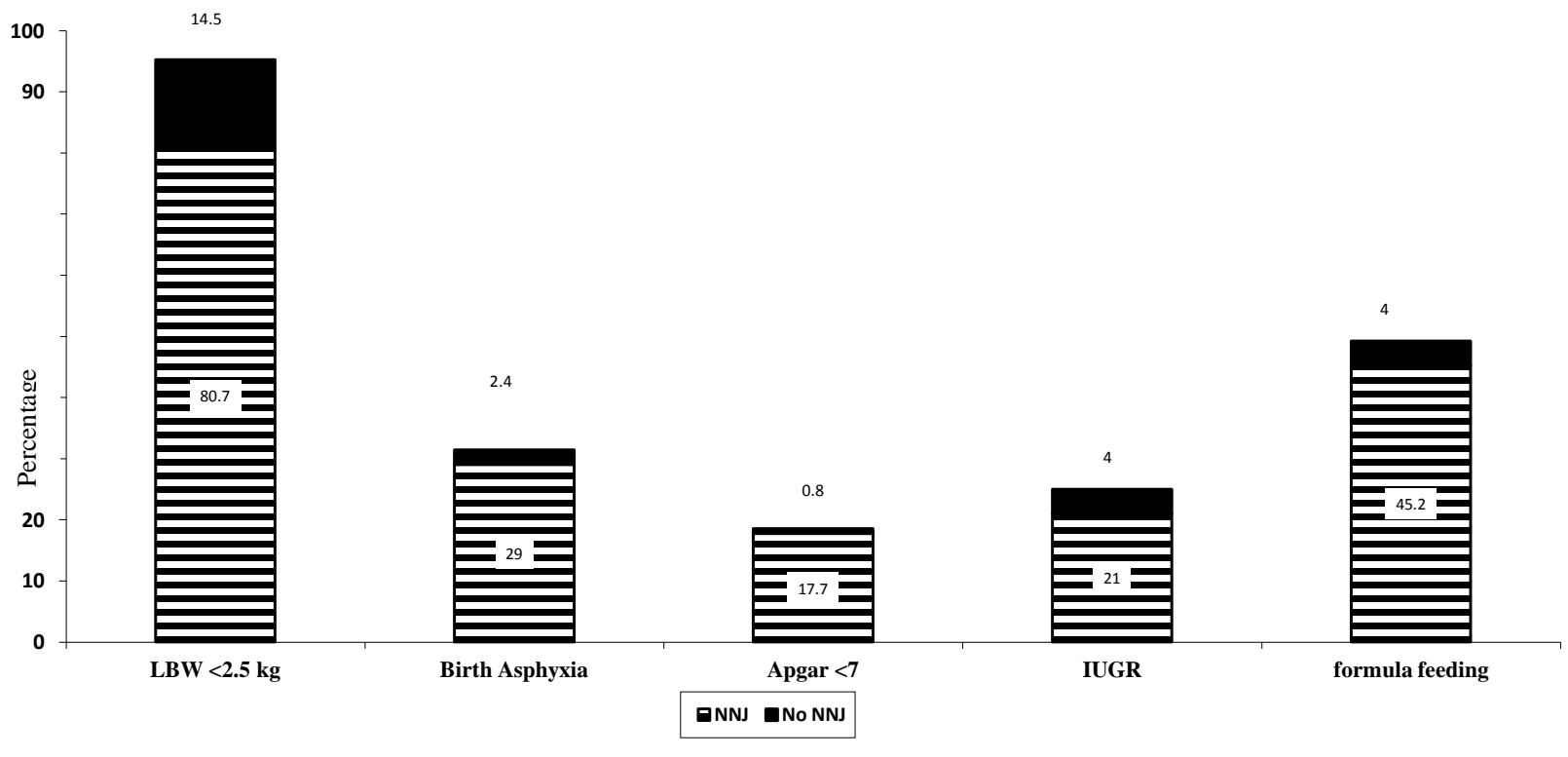

LBW low birth weight $\quad$ IUGR intreauterine growth retardation $\quad$ NNJ neonatal jaundice 
Figure 2: Maternal determinants of neonatal jaundice

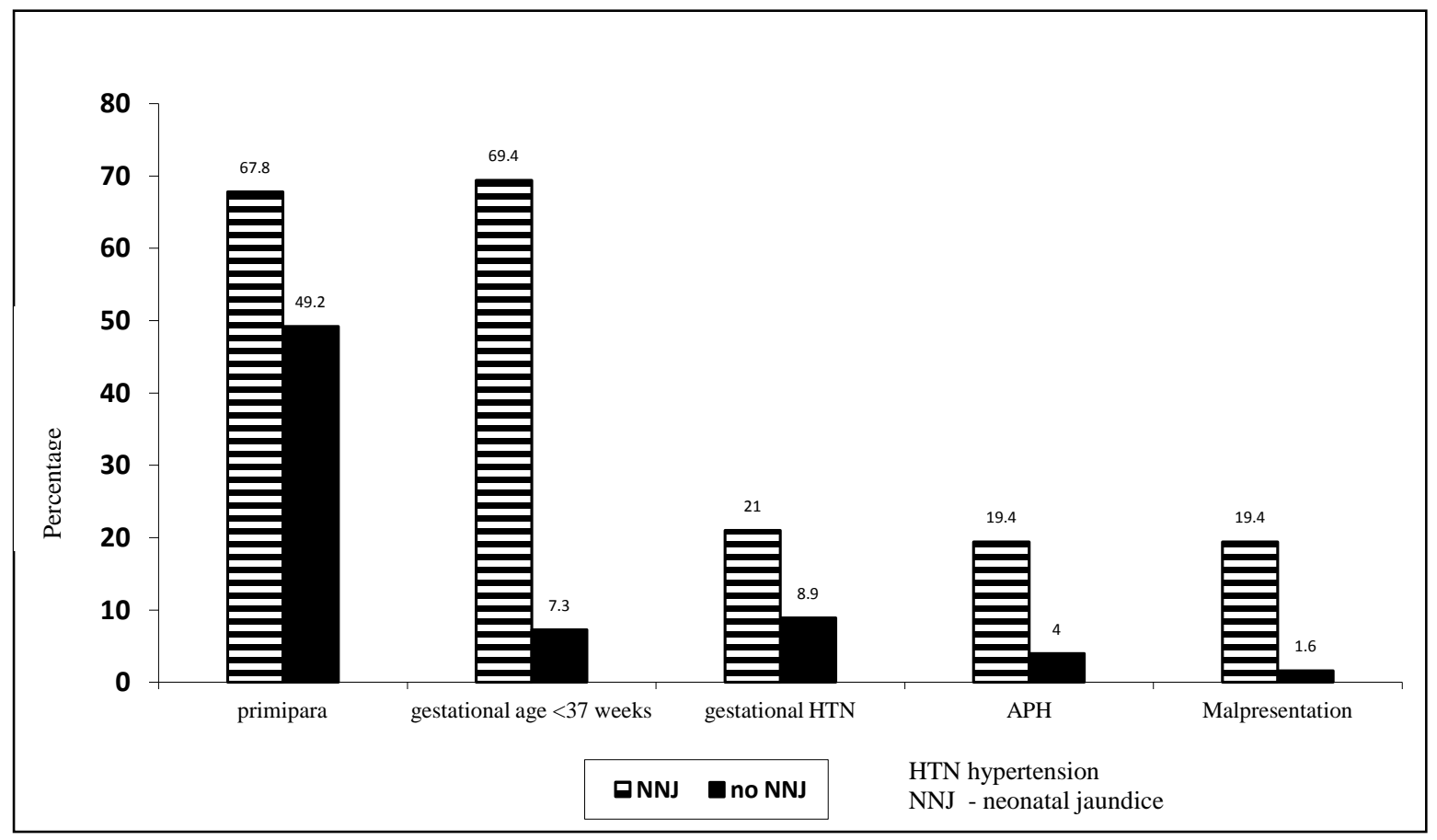

Figure 3: Maternal determinants of neonatal jaundice .. Cont'd

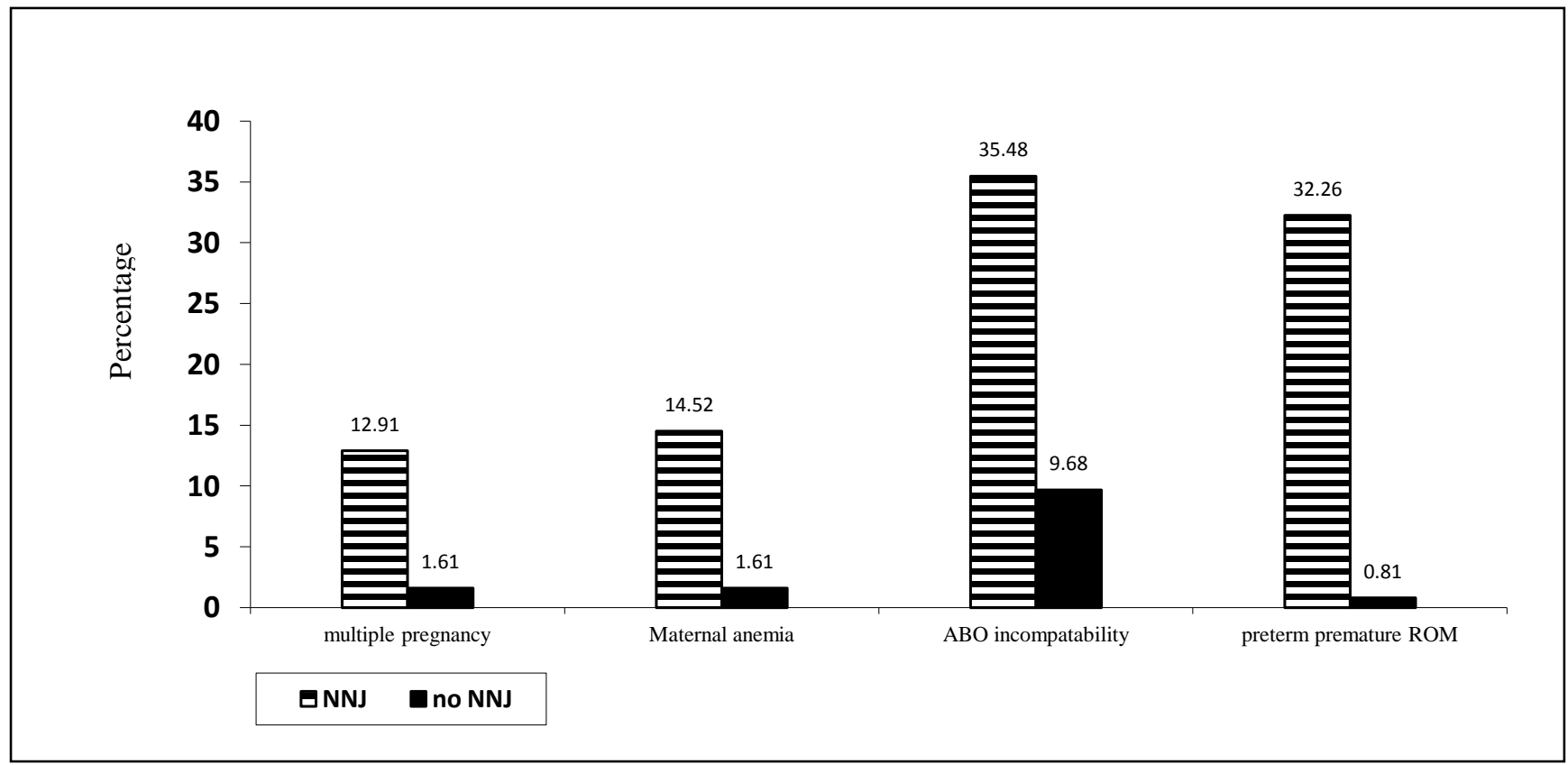

\section{DISCUSSION}

The mean age of the mothers was not significantly different between the mothers of babies born who had neonatal jaundice and in those without occurrence of neonatal jaundice. There was no sex predilection for neonatal jaundice. This is in contrast to the study reported by Garosi E et al and Najib KS et $\mathrm{al}^{7,9}$. Maternal age, maternal education status or frequencies of antenatal visits were non determinants of neonatal jaundice in this study.

The main neonatal determinants with strong association ( Phi +0.65 ) was low birth weight (OR 24.54; 95\% CI $10.98-54.84 \mathrm{P}<0.0001$; Phi +0.65 ) and birth asphyxia ( OR 16.5: 95\% CI 4.63 - $58.76 \mathrm{P}<0.0001$; Phi +0.4), low APGAR 
score < 7 ( OR 26.1 95\%CI 3.28 -207.47 Fishers Exact test 2 tailed $\mathrm{P}=0.0002$; $\mathrm{Phi}+0.32$ )and intrauterine growth retardation (IUGR)(OR 6.31 95\% CI 2.14 -18.66; $p=0.0006$ : Phi +0.27). and prematurity (gestational age less than 37 weeks). Olusanya et al reported low gestational age (OR: 1.71; 95\% CI:1.40-2.11), underweight or weight loss (OR: 6.26; 95\% CI:1.23-31.86) placed the infants at high risk of hyperbilirubinemia and bilirubin induced neurologic dysfunction ${ }^{10}$. Premature babies have higher serum bilirubin levels for a longer time due to hepatic immaturity. Preterm infants also likely to have associated problems like asphyxia, hypoglycemia, hypothermia and acidosis all of which contribute to the development of jaundice. Birth asphyxia as an important cause for neonatal jaundice and kernicterus has been emphasized in the previous study by Murki $\mathrm{S}$ et $\mathrm{al}^{11}$. Similarly low APGAR score $<7$ which indicates some form of asphyxia during delivery were also reported in earlier studies as an important factor which contributes to severe neonatal jaundice.

Prematurity (gestational age $<37$ weeks) had a strong association with neonatal jaundice (OR 28.92: 95\% CI 12.15 - 68.82: $\mathrm{P}<0.0001$ ) with phi of +0.65 indicating strong positive relation ship similar to previous reports ${ }^{9,10,11}$. Primiparity have a higher likely hood of neonatal jaundice in this study (OR 2.17: 95\% CI : 1.15 -4.11). Maternal parity has been found to be a determinant for neonatal jaundice in previous reports as well ${ }^{13,} 14$. However, the Phi was only +0.18 in this study indicating a low positive relationship in this study. Preterm premature rupture of membranes showed a very high likelihood (Phi +0.47) for development of neonatal jaundice in this study similar to the previous reports (OR: $58.57 \mathrm{CI}$ : 7.63 - 449.87; $\mathrm{P}<0.0001)$. ABO incompatibility was also a strong determinant of neonatal jaundice similar to previous reports ${ }^{15,16}$ (OR: 5.13 95\% CI : $2.33-11.31 \mathrm{P}<0.0001$ ) with a Phi value of +0.31 suggestive moderate positive association. Malpresentation also significantly associated with neonatal jaundice (OR 14.64; 95\% CI 3.16 -
67.79; 2 tailed $\mathrm{p}=0.00004$ ) with a Phi +0.32 . Malpresentations are likely to increase the duration of labour and cause birth asphyxia there by leading to neonatal jaundice.

Other determinants in this study for neonatal jaundice included multiple pregnancy, antepartum hemorrhage and maternal anemia. Multiple pregnancy probably act by increased chance of prematurity or low birth weight babies, increase chances of birth asphyxia and increases the chances of neonatal jaundice. Phi values were between +0.24 to +0.26 indicating a positive likely hood albeit low. (Table 4)

The major determinants for neonatal jaundice identified by logistic regression analysis were Preterm premature rupture of membranes , gestational age <37 weeks, APGAR score below 7, Birth weight below 2500grams, Birth asphyxia and multiple pregnancy. The association was less strong in $\mathrm{ABO}$ incompatibility, antepartum hemorrhage and intrauterine growth retardation (IUGR).

Limitations: The study sample was small in size and the event rates were small which resulted in wide confidence intervals in certain parameters analyzed.

\section{CONCLUSIONS}

Neonatal jaundice is one of the most common morbidities during the first few days of life with a potential for devastating neurologic sequelae. The major determinants of neo natal jaundice in this study by logistic regression were preterm premature rupture of membranes, premature delivery <37 weeks, APGAR score <7, Birth asphyxia, Multiple pregnancy, ABO incompatibility, Antepartum hemorrhage and intrauterine growth retardation. It is important to note that the increased awareness of major determinants will enable to formulate and evolve strategies to identify high risk cases and optimize the management strategies to reduce the incidence of neonatal jaundice. 


\section{REFERENCES}

1. Burke BL, Robbins JM, Bird TM, Hobbs CA, Nesmith C, et al. (2009) Trends in hospitalizations for neonatal jaundice and kernicterus in the United States, 19882005. Pediatrics 123:524-5320

2. Hameed $\mathrm{NN}, \mathrm{Na}$ Ma $\mathrm{AM}$, Vilms $\mathrm{R}$, Bhutani VK. (2011) Severe neonatal hyperbilirubinemia and adverse short-term consequences in Baghdad, Iraq. Neonatology 100:57-63.

3. English M, Ngama M, Musumba C, Wamola B, Bwika J, et al. (2003) Causes and outcome of young infant admissions to a Kenyan district hospital. Arch Dis Child 88:438-443.

4. Mwaniki MK, Atieno M, Lawn JE, Newton CR. (2012) Long-term neurodevelopmental outcomes after intrauterine and neonatal insults: a systematic review. Lancet 379:445-452.

5. American Academy of Pediatrics (AAP). (2004) Management of hyperbilirubinaemia in the newborn infant 35 or more weeks of gestation. Pediatrics 114:297316

6. Bhutani VK, Zipursky A, Blencowe H, Khanna R, Sgro M, et al. (2013) Neonatal hyperbilirubinemia and Rhesus disease of the newborn: incidence and impairment estimates for 2010 at regional and global levels. Pediatr Res 74 Suppl 1:86-100.

7. Najib KS, Saki F, Hemmati F, Inaloo S. Incidence, Risk Factors and Causes of Severe Neonatal Hyperbilirubinemia in the South of Iran (Fars Province). Iran Red Cres Med J. 2013; 15(3): 260-3. DOI: 10.5812/ircmj.3337.

8. Huang MJ, Kua KE, Teng HC, Tang KS, Weng HW, Huang CS Risk Factors for Severe Hyperbilirubinemia in Neonates, Pediatr Res 56: 682-689, 2004
9. Garosi E, Mohammedi F, Ranjkesh F, The Relationship between Neonatal jaundice and Neonatal factors and Maternal factors, Iranian Journal of Neonatology, 2016; 7(1); open access; http:/ ijn.mums.ac.j

10. Olusanya BO, Osibanjo FB, Slusher TM, (2015) Risk Factors for Severe Neonatal Hyperbilirubinemia in Low and MiddleIncome Countries: A Systematic Review and Meta-Analysis. PLoS ONE 10(2): 0117229 .

doi:10.1371/journal. pone.0117229

11. Murki S, Kumar P, Majumdar S, Marwaha N, Narang A. (2001) Risk factors for kernicterus in term babies with nonhemolytic jaundice. Indian Pediatr 38:757762

12. Porter ML, Dennis BL, Hyperbilirubinemia in the Term Newborn: Am Fam Physician 2002;65:599-606,613-4

13. Chawla D, Jain S, Dhir S, Rani S. (2012) Risk assessment strategy for prediction of pathological hyperbilirubinemia in neonates. Indian J Pediatr 79:198-201.

14. Scrafford CG, Mullany LC, Katz J, Khatry SK, Leclerq SC, et al. (2013) Incidence of and risk factors for neonatal jaundice among newborns in southern Nepal. Trop Med Int Health 18:1317-1328

15. Arif K, Bhutta ZA. (1999) Risk factors and spectrum of neonatal jaundice in a birth cohort in Karachi. Indian Pediatr 36:487493

16. Kalakheti BK, Singh R, Bhatta NK, Karki A, Baral N. (2009) Risk of neonatal hyperbilirubinemia in babies born to ' $\mathrm{O}$ ' positive mothers: A prospective cohort study. Kathmandu Univ Med J 7:11-15. 